\title{
Uma abordagem experimental e numérica para determinação de curvas de compressão para concreto simples e reforçados com fibras de aço
}

\section{An experimental and numerical approach for determining compression curves for plain and steel fiber reinforced concretes}

José Carlos Nunes Rauecker ${ }^{1}$,Wanderlei Malaquias Pereira Junior ${ }^{2}$, José Júlio de Cerqueira Pituba ${ }^{2}$,Daniel de Lima Araújo ${ }^{3}$

\footnotetext{
${ }^{1}$ Universidade Federal de Goiás - Escola de Engenharia Civil e Ambiental - CEP: 74605-120, Goiânia, Goiás, Brasil.

${ }^{2}$ Universidade Federal de Goiás - Faculdade de Engenharia - Regional Catalão, Catalão, Goiás, Brasil.

${ }^{3}$ Universidade Federal de Goiás - Escola de Engenharia Civil e Ambiental Goiânia, Goiás, Brasil.

e-mail: joserauecker@gmail.com, wanderlei.malaquias.pereira;jr@outlook.com,jjpituba@ufg.br, dlaraujo@ufg.br
}

\section{RESUMO}

A curva tensão-deformação do concreto é importante para o dimensionamento de estruturas, pois por meio dela é possível obter sua resistência à compressão, sua deformação de pico, o módulo de elasticidade e a tenacidade do concreto. Entretanto, essa é uma propriedade que não é comumente determinada nos ensaios de controle de qualidade do concreto, sendo normalmente controlada apenas a resistência à compressão. Contudo, quando se utiliza de métodos mais refinados para projeto de estruturas de concreto, como, por exemplo, a análise não linear física com o emprego do método dos elementos finitos, essa é uma propriedade fundamental para a análise da estrutura. Neste caso, a curva tensão-deformação à compressão deveria ser controlada em laboratório, mesmo quando se utiliza de curvas recomendadas em códigos de projeto. Deste modo, o objetivo deste artigo é apresentar uma metodologia para avaliação da curva completa tensão-deformação à compressão do concreto simples e reforçado com fibras de aço a partir de máquinas de ensaio de baixo custo, disponível na maioria dos laboratórios de controle de qualidade de concreto. Adicionalmente, é apresentada uma metodologia numérica para análise inversa da curva tensão-deformação à compressão com o objetivo de estimar parâmetros para modelagem de estruturas de concreto por meio da mecânica do Dano.

Palavras-chave: Concreto. Fibras de aço. Curva tensão-deformação. Análise inversa. Modelagem numérica.

\section{ABSTRACT}

The stress-strain diagram of concrete is important for the design of concrete structures because compressive strength, peak deformation, modulus of elasticity and toughness can be obtained from this diagram. However, the stress-strain relationship is not commonly determined in concrete quality control trials, and usually, only compressive strength is determined. However, when more refined methods are used for designing concrete structures, such as physical nonlinear analysis with the finite element method, the stress-strain diagram is fundamental for structure analysis. In this case, the compression strain-strain curve should be determined in a laboratory, even if recommended curves from design codes are used. Thus, the objective of this paper is to propose a methodology to evaluate the compressive strain-strain diagram of plain and steel fiber reinforced concretes using low-cost test machines available in most concrete control laboratories. In addition, a numerical method is presented for inverse analysis of the strain-strain diagram, with the objective of estimating parameters for modeling concrete structures by means of damage mechanics.

Keywords: Concrete. Steel fiber. Stress-strain diagram. Inverse analysis. Numerical modeling.

\section{INTRODUÇÃO}

O concreto é o material de construção mais utilizado na atualidade [1]. Isso se dá principalmente pelo seu baixo custo e características vantajosas como sua alta resistência à compressão, boa aderência com o aço, etc. 
Contudo, atualmente o avanço da engenharia tem possibilitado a construção de edificações cada vez mais altas e com arquiteturas complexas, e com a implantação de rígidas normas de desempenho, há uma necessidade crescente de um maior controle tecnológico desde o dimensionamento das estruturas até sua execução e operação.

Para acompanhar o crescimento da complexidade dos projetos estruturais das edificações, foi necessário o aprimoramento das características mecânicas dos materiais estruturais empregados, como também a criação de "novos" materiais com potencial estrutural, como, por exemplo, o concreto com fibras de aço que aumenta a resistência ao impacto, a resistência a fadiga, o controle da fissuração e o comportamento pósfissuração do concreto [2, 3]. Além disso, novas ferramentas de análise estrutural foram desenvolvidas com o objetivo de avaliar com maior precisão os esforços e as deformações nas estruturas de concreto.

Para o bom desempenho de uma estrutura, as propriedades mecânicas do material constituinte devem ser bem estudas e definidas de forma a garantir os requisitos de qualidade, durabilidade e desempenho exigidos nas normativas de projetos como, por exemplo, os exigidos pela ABNT NBR 6118 [4].

Um dos parâmetros mais importantes no controle tecnológico do concreto deveria ser a curva tensãodeformação à compressão [5], que fornece várias informações importantes para elaboração de projetos estruturais, tais como a resistência à compressão, o módulo de elasticidade tangente inicial e secante, a deformação na carga de pico e a tenacidade do concreto. Além disso, para uma adequada análise não linear física de uma estrutura por métodos computacionais é necessário conhecer toda a curva tensão-deformação à compressão do concreto podendo essa ser elaborada via modelagem experimental, numérica ou através de uma integração das duas últimas.

Contudo, devido à necessidade de equipamentos de alto custo para a determinação da curva tensãodeformação à compressão do concreto, normalmente esse ensaio não é realizado para a etapa de projeto nem durante a etapa de controle de qualidade do concreto. Assim, no projeto são utilizadas equações sugeridas em códigos de projeto ou, na ausência dessas, podem ser utilizadas equações empíricas disponíveis na literatura. Para o concreto com fibras, pode ser citado o trabalho o trabalho clássico de CARREIRA E CHU [6] e o código Modelo da FIB [7]. Já para o concreto com fibras de aço, existem diversas expressões na literatura. Muitas dessas curvas são obtidas de regressões não lineares para obtenção de curvas empíricas com a descrição completa da curva tensão-deformação para o concreto. Neste sentido, citam-se os trabalhos de OLIVEIRA JÚNIOR et al. [8], MANSUR et al. [9]; BARROS e FIGUEIRAS [10]; e ARAÚJO [11]. Esse último autor realizou um trabalho com metodologia semelhante à deste artigo, contudo, utilizando uma máquina de ensaio servo-controlada, obtendo a equação empírica (1) para a curva tensão-deformação do concreto reforçado com fibras de aço:

$$
\begin{aligned}
& \frac{\sigma_{c}}{f_{c}}=\frac{k_{1} \cdot \beta \cdot \frac{\varepsilon_{c}}{\varepsilon_{c, l i m}}}{k_{1} \cdot \beta-1+\left(\frac{\varepsilon_{c}}{\varepsilon_{c, l i m}}\right)^{k_{2} \cdot \beta}} \\
& k_{1}=8,241 \cdot f_{c}^{-0,593} \text { Para } V_{f}=0,00 \\
& k_{1}=478,608 \cdot f_{c}^{-1,593} \cdot V_{f}^{0,6577}{ }_{f} \text { Para } 0,00 \% \leq V_{f} \leq 2,00 \% \\
& k_{2}=22,50 \cdot f_{c}^{-0,775} \operatorname{Para}_{f}=0,00 \\
& k_{2}=34,513 \cdot f_{c}^{-0,925} \cdot V_{f}{ }^{0,368} \text { Para } 0,00 \% \leq V_{f} \leq 2,00 \%
\end{aligned}
$$

Nessa expressão, $\sigma_{c}$ é a tensão de compressão do concreto; $\varepsilon_{c}$ é a deformação específica para cálculo da tensão no modelo numérico. Já $f_{c}$ é o valor da tensão máxima de compressão característica do concreto e $\beta$ é um parâmetro material que depende da forma do diagrama de tensão-deformação conforme apresentado em [6]. O valor de $\varepsilon_{c, l i m}$ é dado pela equação (6) dada a seguir.

$$
\varepsilon_{c, l i m}=0,001446 . f_{c}^{0,114}+\frac{0,0271 \cdot V_{f}^{1,5269}}{f_{c}} \operatorname{com} V_{f} \text { em } \% \text { e } f_{c} \text { em MPa }
$$


Além da determinação experimental, a modelagem numérica tem sido bastante utilizada para a caracterização do comportamento de materiais em geral. PEREIRA JUNIOR et al.[3] cita a importância da escolha adequada de modelos numéricos para representação de fenômenos naturais de sistemas ou materiais e que a modelagem computacional é uma ferramenta essencial para que engenheiros possam melhorar os processos de projeto, de forma a reduzir custos através de simulações preditivas confiáveis [12].

Assim, o objetivo deste artigo é apresentar algumas estratégias para determinação da curva tensãodeformação à compressão do concreto a partir de duas propostas: (a) ensaio experimental em equipamento de baixo custo; (b) análise inversa. Para este artigo foram utilizados como materiais estruturais o concreto simples e o concreto reforçado com fibras de aço.

Para a análise experimental, foi adaptada da literatura uma metodologia de ensaio para ser utilizada em uma máquina de ensaio eletromecânica de baixo custo. Isso deve-se ao fato de que na maior parte dos trabalhos da literatura, as curvas tensão-deformação do concreto são obtidas de máquinas de ensaio servocontroladas de alto custo, o que dificulta a determinação da curva tensão-deformação do concreto na grande maioria dos laboratórios de tecnologia do concreto existentes no Brasil que possuem apenas máquinas eletromecânicas.

Para a abordagem por meio da análise inversa, foi desenvolvido um procedimento inverso de otimização para estimação dos parâmetros de um modelo numérico de dano isotrópico. Com isso, obtêm-se os parâmetros da curva tensão-deformação que pode ser utilizada em modelagens computacionais de estruturas de concreto que empregam a teoria da Mecânica do Dano.

O artigo está organizado da seguinte forma: na seção 2 é apresentada a metodologia para determinação experimental da curva tensão-deformação do concreto. A seção 3 apresenta os conceitos para realização de uma análise inversa e na seção 4 são apresentados e discutidos os resultados. Finalmente, na seção 5 são delineadas as conclusões e proposições futuras acerca da temática.

\section{PROGRAMA EXPERIMENTAL}

Neste item são descritos os materiais e métodos utilizados para a determinação da curva tensão-deformação para o concreto. Aqui são apresentados aspectos sobre os ensaios normatizados realizados neste trabalho, bem como o método de ensaio para determinação da curva tensão-deformação que foi adaptado para uso em uma máquina de ensaio eletromecânica de baixo custo.

\subsection{Caracterização dos materiais empregados}

Para a confecção dos corpos-de-prova foi utilizado Cimento Portland Composto com Filler (CP II F-40). É um cimento com alto grau de finura, proporcionando maiores resistências em todas as idades, porém apresenta maior calor de hidratação, o que pode gerar fissuras de retração. Foram utilizados também agregados miúdos dos tipos areia natural e artificial, que foram caracterizados seguindo as normas ABNT NBR 7211 [13] e ABNT NBR 7251 [14], e agregado graúdo com dimensão máxima característica de 12,5 mm, cuja caracterização seguindo a norma ABNT NBR NM 53 [15] apresenta-se na Tabela 1.

Tabela 1: Propriedades físicas dos agregados.

\begin{tabular}{l|l|l|l}
\hline ENSAIOS & AREIA NATURAL & AREIA ARTIFICIAL & AGREGADO GRAÚDO \\
\hline Módulo de Finura Médio & 2,17 & 2,91 & 2,04 \\
\hline Massa Específica $\left(\mathrm{g} / \mathrm{cm}^{3}\right)$ & 2,39 & 2,28 & 2,62 \\
\hline Absorção de Água $(\%)$ & -- & -- & 0,85 \\
\hline
\end{tabular}

As fibras de aço utilizadas foram do tipo DRAMIX RC 65/35. Suas propriedades são apresentadas na Tabela 2.

Tabela 2: Propriedades da fibra de aço DRAMIX RC 65/35 (BELGO BEKAERT [16]). 


\begin{tabular}{l|l}
\hline Comprimento $\left(\mathrm{L}_{\mathrm{f}}\right.$ em $\left.\mathbf{~ m m}\right)$ & 35,00 \\
\hline Diâmetro $\left(\mathrm{D}_{\mathrm{f}}\right.$ em $\left.\mathbf{~ m m}\right)$ & 0,55 \\
\hline Relação de aspecto $\left(\mathrm{L}_{\mathrm{f}} / \mathrm{D}_{\mathrm{f}}\right)$ & 65,00 \\
\hline Massa específica $\left(\mathbf{g} / \mathrm{cm}^{3}\right)$ & 7,85 \\
\hline
\end{tabular}

O traço utilizado está especificado na Tabela 3. Foram realizadas duas concretagens com a adição de dois diferentes volumes de fibras de aço $\left(0,50 \%\right.$ e $1,50 \%$, isto é, $39,08 \mathrm{~kg} / \mathrm{m}^{3}$ e $117,21 \mathrm{~kg} / \mathrm{m}^{3}$, respectivamente), além de uma concretagem com traço de referência sem adição de fibras $\left(V_{f}=0,00 \%\right)$. A trabalhabilidade do concreto foi assegurada por meio do uso de aditivo superplastificante sintético, com porcentagem variável em função do volume de fibras utilizado em cada traço.

Tabela 3: Composição da matriz de concreto utilizada.

\begin{tabular}{l|l}
\hline MATERIAL & QUANTIDADE $\left(\mathbf{k g} / \mathbf{m}^{3}\right)$ \\
\hline Cimento CP II F 40 & 480,77 \\
\hline Água & 169,62 \\
\hline Sílica Ativa & 18,94 \\
\hline Areia Natural & 377,21 \\
\hline Areia Artificial & 348,37 \\
\hline Agregado Graúdo & 832,12 \\
\hline Fibras de Aço & Variável $\left(39,08 \mathrm{~kg} / \mathrm{m}^{3}\right.$ e $\left.117,21 \mathrm{~kg} / \mathrm{m}^{3}\right)$ \\
\hline Aditivo Superplastificante & Variável \\
\hline Relação água/cimento equivalente & 0,35 \\
\hline
\end{tabular}

\subsection{Métodos de ensaio}

$\mathrm{O}$ concreto foi caracterizado quanto às suas propriedades no estado fresco, isto é, abatimento do tronco de cone, massa específica e teor de ar. $\mathrm{O}$ abatimento do tronco de cone foi obtido seguindo o procedimento da ABNT NBR NM 67 [17], como mostrado na Figura 1. No caso dos traços com fibras, o abatimento foi determinado em dois momentos, isto é, para a matriz, antes da adição das fibras de aço, e depois de adicionada e concluída a homogeneização das fibras de aço. A massa específica e o teor de ar incorporado foram determinados seguindo o procedimento da norma ABNT NBR 9833 [18], conforme a Figura 1.

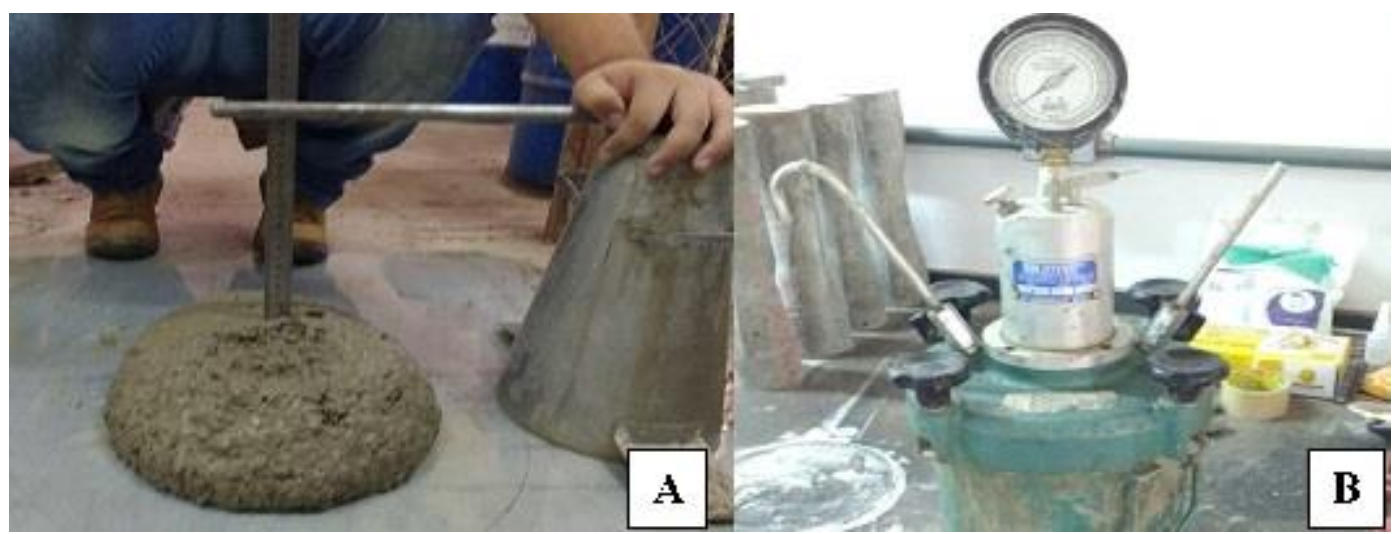

Figura 1: Medições do abatimento do tronco de cone (a), segundo a ABNT NBR NM 67 [17] e do teor de ar incorporado e da massa específica (b), segundo a norma ABNT NBR 9833 [18].

O concreto também foi caracterizado quanto às suas propriedades no estado endurecido, isto é, resistência à compressão, módulo de elasticidade e curva tensão-deformação. Para isso, foram moldados corposde-prova cilíndricos com dimensões de $100 \mathrm{~mm}$ x $200 \mathrm{~mm}$ e de $150 \mathrm{~mm}$ x $300 \mathrm{~mm}$, que foram mantidos em câmara úmida com temperatura média de $22^{\circ} \mathrm{C}$ e umidade maior que $95 \%$ até a data do ensaio. 
A resistência à compressão foi determinada seguindo o procedimento da norma ABNT NBR 5739 [19] utilizando seis corpos de prova. Foi empregada uma prensa eletromecânica com capacidade máxima de $2000 \mathrm{kN}$, adotando uma velocidade de carregamento de $0,55 \mathrm{MPa} / \mathrm{s}$ (Figura 2a). Os corpos-de-prova ensaiados tinham a dimensão de $100 \mathrm{~mm}$ x $200 \mathrm{~mm}$ e foram moldados segundo a norma ABNT NBR 5738 [20].

Para a determinação do módulo de elasticidade do concreto, foram ensaiados três corpos-de-prova cilíndricos de dimensões de $150 \mathrm{~mm}$ x $300 \mathrm{~mm}$ em uma prensa eletromecânica de capacidade de $2000 \mathrm{kN}$. O ensaio foi orientado pela ABNT NBR 8522 [21], utilizando um extensômetro mecânico de configuração tripla, com espaçamento de $120^{\circ}$ entre cada extensômetro, para medir as deformações nos corpos-de-prova (Figura 2b).

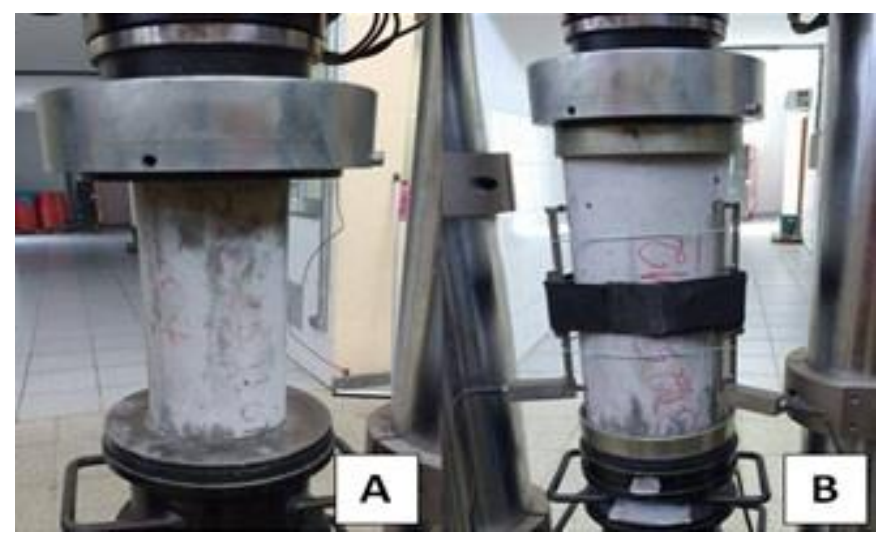

Figura 2: (a) Ensaios de resistência à compressão segundo a norma ABNT NBR 5739 [19]; (b) módulo de elasticidade segundo a norma ABNT NBR 8522 [21].

O ensaio para determinação da curva completa tensão-deformação, incluindo a região pós-pico, foi desenvolvido neste trabalho a partir da metodologia descrita no trabalho de MANSUR et al. [22], seguindo, ainda, algumas das recomendações da RILEM [23]. Nessa última bibliografia, é recomendado que sejam colocados três LVTD's, ou extensômetros elétrico de resistência (com pelo menos um terço da altura do corpo de prova), com espaçamento de $120^{\circ}$ entre eles (Figura 3). Entretanto, a leitura dos transdutores ou dos extensômetros pode ser utilizada somente para determinar a curva ascendente, pois após o pico de carregamento começam a aparecer as macrofissuras no corpo de prova. Elas geram instabilidade e erros nas medições, assim é necessário utilizar outro meio para medir as deformações na região pós-pico.

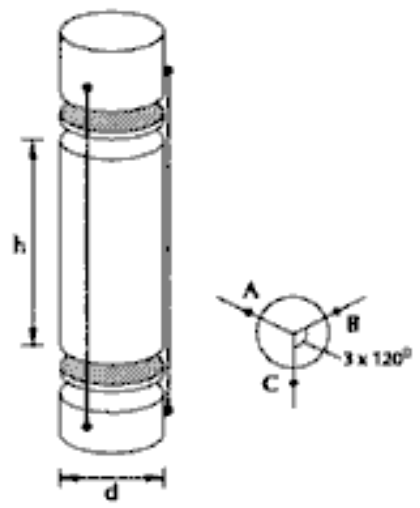

Figura 3: Esquema da colocação dos extensômetros segundo RILEM [23].

O método da RILEM [23] recomenda que os ensaios sejam realizados em uma máquina servocontrolada. Para a montagem do aparato é necessário observar se os pratos têm, aproximadamente, o mesmo raio que o corpo de prova. Além disso, eles devem possuir de 50 a $100 \mathrm{~mm}$ de espessura. Entre os pratos e o corpo de prova é preciso colocar um elemento de redução de atrito, que geralmente é uma camada de graxa coberta por uma folha de teflon com espessura de $100 \mu \mathrm{m}$. Então, é aplicada uma pequena carga $(0,50-1,00$ $\mathrm{kN}$ ) para garantir que o corpo de prova fique firme e não se mova da posição inicial. São conferidos os exten- 
sômetros e LVDT's e, então, aumenta-se a carga para algo em torno de $10 \mathrm{kN}$, podendo-se assim iniciar o ensaio.

O arranjo experimental deste artigo é semelhante ao da RILEM [23] e de MANSUR et al. [22], porém adaptados para serem realizados em uma prensa hidráulica comandada por uma máquina de ensaio eletromecânica de baixo custo. A máquina de ensaio utilizada nos ensaios possuía um software modificado que permitia o ensaio em ciclo fechado, com controle da velocidade de deslocamento da máquina ou de transdutores fixados no corpo de prova. Para que a prensa hidráulica pudesse realizar o ensaio de compressão também em ciclo fechado, foram adaptados dois transdutores de deslocamento da máquina de ensaio, os quais foram apoiados no pistão da prensa, diagonalmente opostos. Além disso, a alimentação do óleo do pistão foi modificada, trocando-se a mangueira flexível de alimentação por uma tubulação rígida. Na parte superior, o corpo de prova reagia em uma rótula acoplada a uma célula de carga que registrava a força aplicada durante o ensaio. Na Figura 4 é apresentado o arranjo do ensaio.

Foram realizados vários testes nesse arranjo de ensaio, tendo sido determinada uma velocidade de subida do pistão de $0,001 \mathrm{~mm} / \mathrm{s}$, e ganho da máquina igual a 1 , que permitia obter uma resposta pós-pico estável para corpos de prova de concreto de $150 \mathrm{~mm}$ x $300 \mathrm{~mm}$ e com resistência à compressão de até $70 \mathrm{MPa}$.

Para acompanhar a deformação do corpo de prova de concreto antes do pico de resistência, foram colados três extensômetros elétricos de resistência (120 $\Omega$ ), uniaxiais, com $80 \mathrm{~mm}$ de comprimento, orientados na direção da altura do corpo de prova e espaçados $120^{\circ}$ entre si (Figura 4). Eles foram colados equidistantes das extremidades do corpo de prova. Os extensômetros foram recobertos com silicone e depois com fita isolante para evitar danos nos mesmos durante o manuseio do corpo de prova.

Os corpos de prova de concreto tiveram, ainda, suas extremidades retificadas para minimizar os efeitos de borda e deixar as duas superfícies paralelas. Assim, procurou-se reduzir os efeitos de flexão no corpo de prova durante a aplicação do carregamento. Depois, eles foram revestidos com plástico filme de modo a evitar que o corpo de prova se desmanchasse ao final do ensaio.

Para reduzir a altura livre da prensa, que era de cerca de $600 \mathrm{~mm}$, foram utilizados três apoios metálicos cilíndricos, com diâmetro pouco maior que o corpo de prova e com altura de $100 \mathrm{~mm}$ cada. Esses apoios possuíam um ressalto para evitar o escorregamento dos mesmos durante o ensaio. Entre o corpo de prova e os apoios da prensa foram utilizados dois pratos de aço para distribuir a força uniformemente no corpo de prova. Foi aplicada uma fina camada de graxa e colocada uma folha de teflon para reduzir o atrito entre esses pratos e o corpo de prova (Figura 5). Buscou-se, assim, evitar o confinamento do corpo de prova nas extremidades conforme recomendado pela RILEM [23].
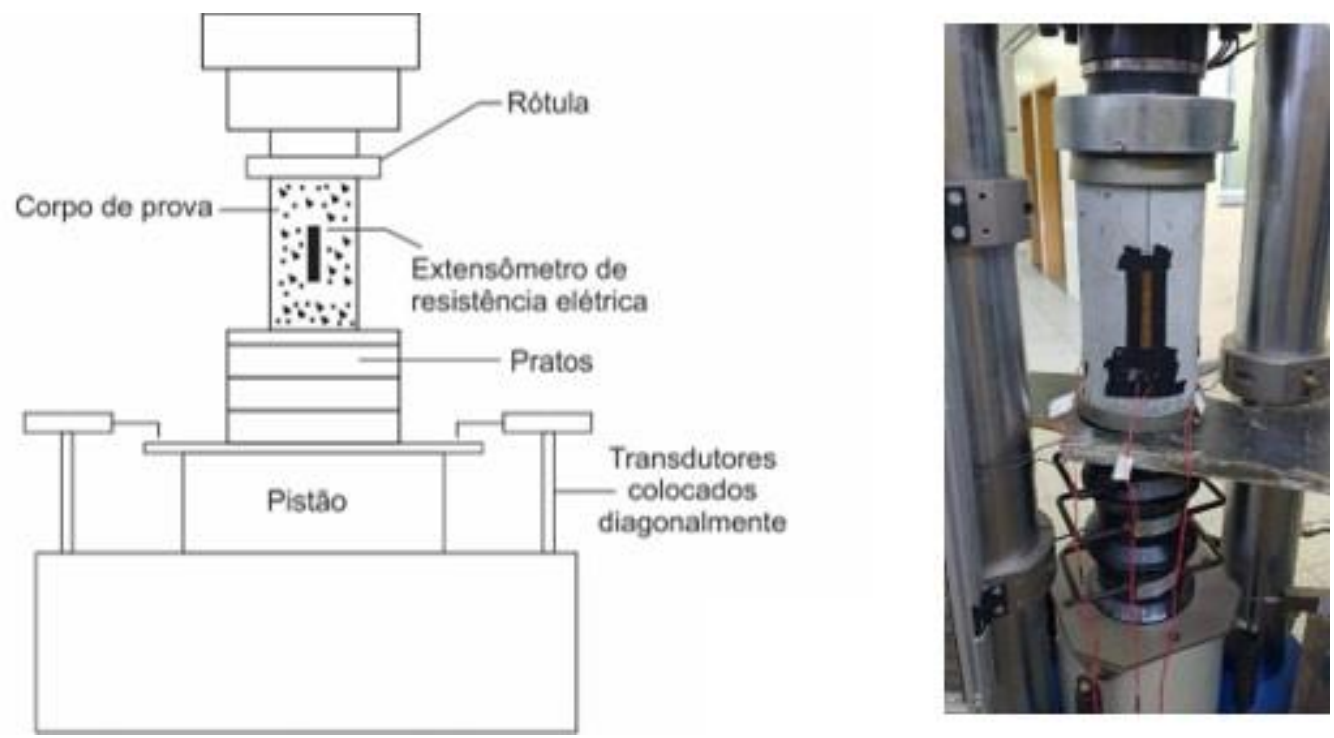

Figura 4: Esquema de montagem do ensaio para determinação da curva tensão-deformação. 


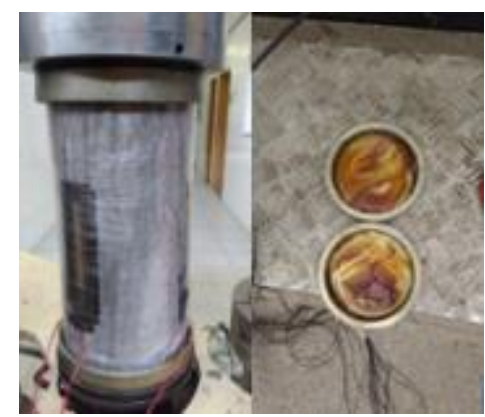

Figura 5: Corpo de prova pronto para ser ensaiado e preparação da superfície de contato com os pratos metálicos.

Sendo $\Delta_{t p}$ o deslocamento medido pelos transdutores entre os pratos inferior e superior da prensa, $\Delta_{c o}$ o deslocamento devido à deformação real do corpo de prova (de comprimento $L_{0}$ ), $\Delta_{m}$ o deslocamento devido à deformação dos apoios metálicos da máquina e $\Delta_{e}$ a deformação causada pelos efeitos de borda no corpo de prova, tem-se que:

$$
\Delta_{t p}=\Delta_{c}+\Delta_{a}, \text { onde } \Delta_{a}=\Delta_{m}+\Delta_{e}
$$

Rearranjando essa equação, tem-se:

$$
\Delta_{a}=\Delta_{t p}-\varepsilon \cdot L_{0}=\frac{\sigma}{E_{t p}} L-\varepsilon \cdot L_{0}
$$

Sendo $L$ a distância entre os pratos inferior e superior da prensa, $\sigma$ a tensão aplicada, e $E_{t p}$ o módulo de elasticidade tangente inicial que vem da curva tensão-deformação obtida dos transdutores fixado no pistão da prensa (Figura 6). No caso da prensa utilizada nesse trabalho, foram colocados três apoios de aço para reduzir a altura livre de ensaio $\left(L_{l}=300 \mathrm{~mm}\right)$. Logo, a distância L era dividida em duas parcelas, uma relativa à altura do corpo de prova $\left(L_{0}=300 \mathrm{~mm}\right)$ e outra relativa à altura dos três apoios de aço. A deformação $\varepsilon$ do corpo de prova é obtida da tensão aplicada $\sigma$ e do módulo de elasticidade inicial real do concreto $\left(E_{c 0}\right)$. Unindo as equações (7) e (8), chega-se na equação (9):

$$
\Delta_{c}=\Delta_{t p}-\left(\frac{\sigma}{E_{t p}}-\frac{\sigma}{E_{c o}}\right) L_{0}-\frac{\sigma}{E_{t p}} L_{1}
$$

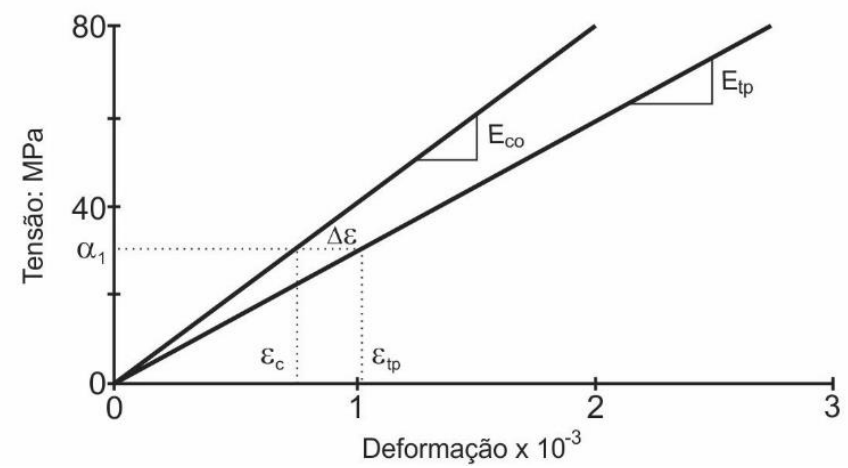

Figura 6: Módulo de elasticidade derivado da leitura dos transdutores $\left(E_{t p}\right)$ e módulo de elasticidade real do corpo de prova $\left(E_{c 0}\right)$.

Dividindo a equação (9) por $L_{0}$, obtém-se a equação (10), onde $\epsilon_{c}$ é a deformação real no corpo de prova de concreto a qualquer nível de tensão, $\epsilon_{t p}$ é a deformação medida pelos transdutores fixados no pistão da prensa e a parcela entre parênteses é o fator de correção sugerido por Mansur et al. [22]. O último termo é o fator de correção que aparece neste trabalho devido aos apoios metálicos posicionados entre o corpo de prova e os pratos da prensa. 


$$
\epsilon_{c}=\epsilon_{t p}-\left(\frac{1}{E_{t p}}-\frac{1}{E_{c o}}\right) \sigma-\frac{\sigma}{E_{t p, a}} \frac{L_{1}}{L_{0}}
$$

Tendo em vista que os transdutores de deslocamento que controlavam o ensaio foram posicionados no pistão da prensa, neles era registrado, também, a deformação dos apoios do corpo de prova, bem como as folgas de montagem entre as peças metálicas da prensa. Para corrigir essas deformações e poder determinar a deformação real do corpo de prova de concreto, inicialmente foi realizado o ensaio de um cilindro metálico de $100 \mathrm{~mm}$ de diâmetro e $300 \mathrm{~mm}$ de altura. Nele foram colados três extensômetros elétricos de resistência na direção axial com comprimento de $80 \mathrm{~mm}$. Foram também colados seis extensômetros uniaxiais na direção horizontal, com comprimento de $5 \mathrm{~mm}$, sendo quatro próximos das extremidades do cilindro e dois à meia altura (Figura 7). Esse cilindro foi ensaiado em triplicata com carregamento ascendente e descendente, até uma tensão de aproximadamente $114 \mathrm{MPa}$ e a uma velocidade de $0,01 \mathrm{~mm} / \mathrm{s}$. Ele permaneceu em regime elástico linear durante todo o ensaio.

O objetivo do ensaio desse cilindro de aço era obter o valor do módulo de elasticidade dos apoios $\left(E_{t p, a}\right)$ e um coeficiente de correção $\left(K_{c o r r}\right)$ que levasse em conta as folgas existentes no esquema de montagem do ensaio. Para isso, a deformação $\varepsilon_{c}$ da equação (10) foi igualada com a deformação registrada nos extensômetros elétricos de resistência na direção axial colados no cilindro de aço. As folgas de montagem também resultam em um trecho inicial de acomodação, que foi excluída após se obter o trecho elástico linear do

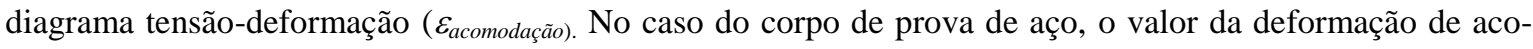
modação no arranjo de ensaio foi avaliado em $0,14 \%$. Assim, a deformação real no corpo de prova de concreto para qualquer nível de tensão pode ser estimada pela equação (11):

$$
\epsilon_{c}=\epsilon_{t p}-\left(\frac{1}{E_{t p}}-\frac{1}{E_{c o}}\right) \sigma-\frac{\sigma}{E_{t p, a}} K_{c o r r}-\varepsilon_{\text {acomodação }}
$$

No caso do equipamento utilizado nos ensaios dessa pesquisa, o ensaio de calibração resultou em $E_{t p a, a}=$ $30247 \mathrm{MPa}$ e no seguinte polinômio de correção $\left(-0,2<K_{\text {corr }}<0,05\right)$ :

$$
\begin{gathered}
K_{\text {corr }}=5,928 \times 10^{-10} \sigma^{5}-2,314 \times 10^{-7} \sigma^{4}+3,542 \times 10^{-5} \sigma^{3}-2,66 \times 10^{-3} \sigma^{2} \\
+9,713 \times 10^{-2} \sigma-1,3292 \quad\left(R^{2}>0,97\right)
\end{gathered}
$$

Vale ressaltar que esse polinômio vale apenas para o arranjo e para a máquina utilizada no ensaio dessa pesquisa, devendo ser determinado para cada máquina em que forem realizados os ensaios dos corpos de prova de concreto. Outra consideração adotada é que o valor do módulo de elasticidade inicial real do concreto $\left(E_{c 0}\right)$ foi obtido da média de três corpos de prova ensaiados conforme a prescrição da ABNT NBR 8522 [21] e não dos extensômetros elétricos colados no corpo de prova.
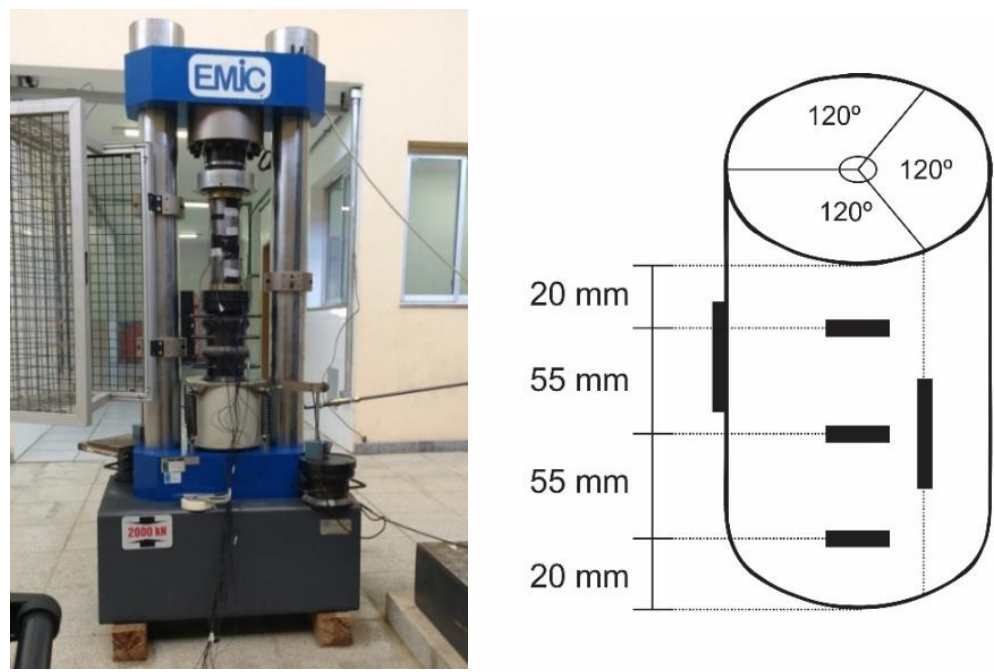

Figura 7: Arranjo do ensaio preliminar com o cilindro de aço para determinação dos fatores de correção da prensa. 
Os extensômetros horizontais colados no cilindro de aço foram utilizados para avaliar a eficiência do tratamento da interface para a eliminação do atrito entre o corpo de prova e os pratos metálicos. Ao final do ensaio, observou-se uma diferença de apenas $1,87 \%$ entre a deformação circunferencial a meia altura e a deformação circunferencial nas extremidades do cilindro, o que mostra a eficiência do tratamento da interface (graxa mais folha de teflon) no sentido de evitar o confinamento das extremidades do corpo de prova. Esse arranjo para verificação do confinamento também foi utilizado em dois ensaios de corpos de prova de concreto, tendo sido obtido o mesmo resultado.

\section{ANÁLISE INVERSA PARA DETERMINAÇÃO DA CURVA TENSÃO-DEFORMAÇÃO DO CONCRETO.}

O problema inverso consiste em determinar as causas a partir de determinados efeitos. A abordagem inversa via processo de otimização tem sido usada como uma alternativa satisfatória para a obtenção de curvas de comportamento de materiais ou sistemas em geral [24-27]. Para este artigo foi escolhido o método de colônia de vagalumes proposto por YANG [28] acoplado ao modelo de dano de MAZARS e PIJAUDIER-CABOT [29] para determinação dos parâmetros da curva tensão-deformação do concreto submetido à compressão uniaxial.

O modelo proposto por MAZARS e PIJAUDIER-CABOT [29] aplica-se a situações de carregamento radial ou crescente, em forma proporcional a certo parâmetro, e admite as seguintes hipóteses fundamentais:

a) localmente, o dano é dado por um estado de alongamento e representado por uma variável escalar;

b) a evolução do dano ocorre quando um valor de referência para o "alongamento equivalente" ̌̌ é superado;

c) o concreto com dano comporta-se como um meio elástico.

A forma geral da Lei de evolução de dano para o modelo é descrita pelas equações (13) e (14):

$$
\begin{aligned}
& D_{T}=1-\frac{\varepsilon_{d 0}\left(1-A_{T}\right)}{\tilde{\varepsilon}}-\frac{A_{T}}{\exp \left[B_{T}\left(\tilde{\varepsilon}-\varepsilon_{d 0}\right)\right]} \\
& D_{C}=1-\frac{\varepsilon_{d 0}\left(1-A_{C}\right)}{\tilde{\varepsilon}}-\frac{A_{C}}{\exp \left[B_{C}\left(\tilde{\varepsilon}-\varepsilon_{d 0}\right)\right]}
\end{aligned}
$$

Nessas equações, $A_{T}$ e $B_{T}$ são parâmetros característicos do material em tração uniaxial, $A_{C}$ e $B_{C}$ são parâmetros do material em compressão uniaxial. Esses parâmetros podem ser identificados a partir de curvas tensão-deformação ou obtidas de ensaios com deformação controlada. O valor de $\varepsilon_{d 0}$ é a deformação referente à tensão de pico para o ensaio de tração direta.

\subsection{Algoritmo de colônia de vagalumes}

Para aplicação dos conceitos de otimização foi utilizado um algoritmo heurístico baseado em interação social de vagalumes denominado de Firefly Algorithm (FA) ou Algoritmo de Colônia de Vagalumes (ACV), desenvolvido por YANG [28]. A proposta de YANG [28] é baseada nos algoritmos tipo Enxame ou Swarm inicialmente desenvolvido KENNEDY e EBERHART [30] com o nome de Particle Swarm Optmization (PSO).

$\mathrm{O}$ ACV é inspirado na bioluminescência dos vagalumes e as interações ocorridas entre os indivíduos devido a esse fator. Portanto, o processo de otimização do ACV é baseado no modo como um vagalume emite luz e como os demais percebem essa luz. Segundo YANG [28], na construção do ACV algumas simplificações em relação ao fenômeno de bioluminescência dos vagalumes são assumidas. Estas simplificações podem ser resumidas como:

a) Presume-se que todos os vagalumes têm um único sexo e, independentemente de possuir um único sexo, são atraídos entre si;

b) A capacidade de atração de cada vagalume é proporcional ao seu brilho, e este diminui de acordo com o aumento da distância entre os indivíduos da população;

c) No caso de não existência de nenhum vagalume mais brilhante que outros, os vagalumes irão se mover aleatoriamente;

d) A intensidade de cada vagalume é determinada pela avaliação da função objetivo. 
A Figura 8a apresenta o fluxograma do ACV e suas demais particularidades enquanto a Figura 8b apresenta a topologia de círculo para a movimentação dos vagalumes. A equação (15) apresenta o modelo adotado para o movimento da população $n$-dimensional de vagalumes.

$$
x_{i}^{t}=x_{i}^{t-1}+\beta \cdot\left(x_{j}^{t-1}-x_{i}^{t-1}\right)+\alpha \cdot(\text { rand }-0,5)
$$

O valor de $\beta$ é dado pela equação (16) e é tido como a atratividade percebida pelo vagalume. Tal valor é proposto em FISTER et al. [31]. O valor de $\beta_{0}$ é tido como a atratividade para uma distância $r=0$ (entre os vagalumes $i$ e $j$ ) e $\gamma$ é o parâmetro de absorção da luz - $\gamma \in[0, \infty)$. De acordo com GOMES e RODRIGUES [32], para a maioria das aplicações tem-se $\gamma \in\left[0,1\right.$ 10,0]. Para as simulações deste trabalho foi adotado $\beta_{0}=$ 1,00 .

$$
\begin{aligned}
& \beta=\beta_{\min }+\left(\beta_{0}-\beta_{\text {min }}\right) \cdot e^{-\gamma \cdot r_{i j}{ }^{2}} \\
& r_{i j}=\sqrt{\sum_{i=1}^{N P}\left(x_{i}-x_{j}\right)^{2}}
\end{aligned}
$$

O terceiro termo da equação (15) corresponde a parte probabilística do processo de otimização, onde o parâmetro $\alpha \in[0, \infty)$ é tido como o passo do algoritmo. O termo rand é um vetor de variáveis aleatórias que varia entre 0 e 1 .

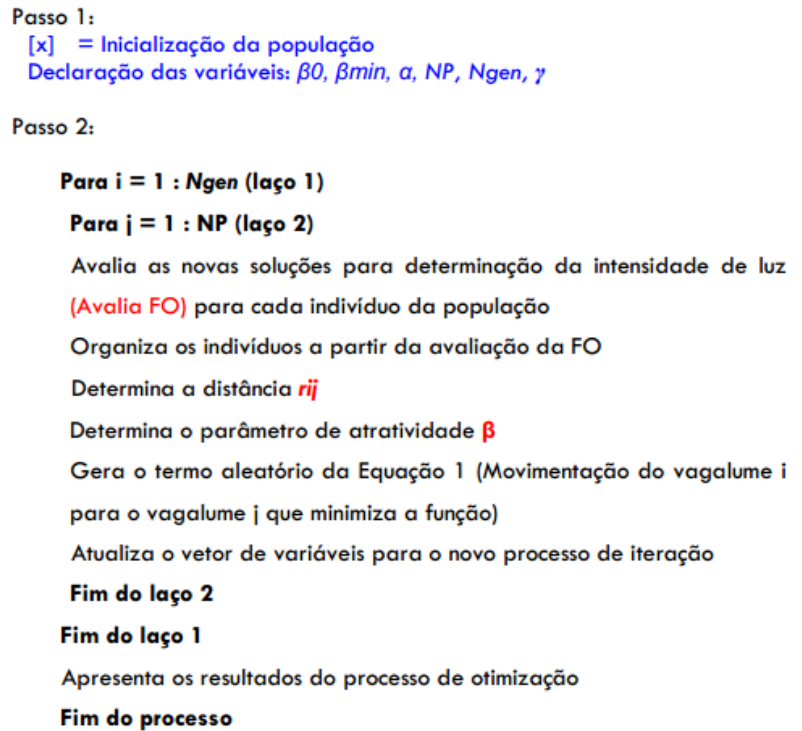

Fonte: Próprio autor

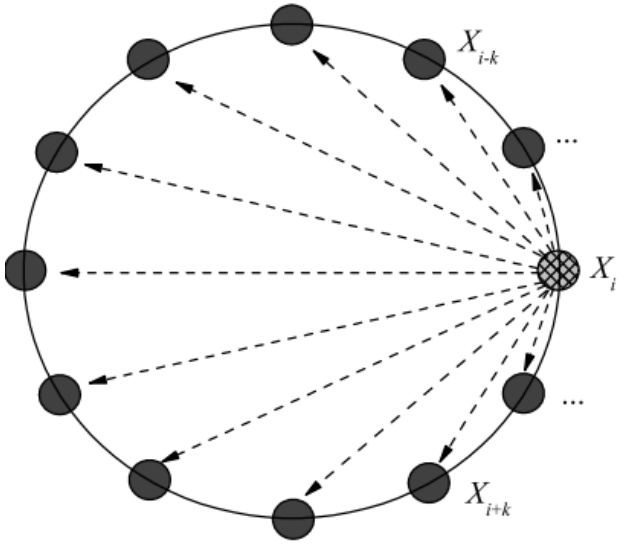

Fonte: Wang et al. [33]

Figura 8: Funcionamento do algoritmo de Colônia de Vagalumes: (a) Fluxograma do algoritmo de Colônia de Vagalumes; (b) Topologia de círculo que representa o movimento do vagalume.

\section{RESULTADOS E DISCUSSÃO}

Nessa seção são apresentados os resultados obtidos assim como as análises pertinentes à problemática investigada. Primeiramente, faz-se a apresentação das propriedades do concreto no estado fresco e endurecido. Logo após são exibidas as curvas tensão-deformação de cada corpo de prova ensaiado. De posse dessas curvas, são obtidos os parâmetros da curva tensão-deformação pela análise inversa. 


\subsection{Propriedades do concreto no estado fresco}

Os resultados dos ensaios do concreto no estado fresco são mostrados na Tabela 4. Observa-se que o volume de fibras adicionado à matriz do concreto influenciou todos os parâmetros quando comparado ao concreto simples. O abatimento da matriz do Traço 2 foi ligeiramente reduzido com a adição de 0,50\% de fibras. Entretanto, quando adicionados $1,50 \%$ de fibras, houve uma redução significativa no valor do abatimento da matriz do Traço 3, fato que é explicado pelo intertravamento macroscópico das partículas formadoras do compósito pelas fibras de aço. Além disso, pode-se perceber um aumento crescente da massa específica do concreto, graças a adição das fibras. Por fim, houve uma diminuição no teor de ar incorporado, que pode ser explicado pelo fato das fibras ocuparem alguns espaços vazios na matriz do concreto, que antes eram preenchidos por ar.

Tabela 4: Caracterização do concreto no estado fresco.

\begin{tabular}{c|c|c|c|c|c|c}
\hline & \multicolumn{2}{|c|}{$\begin{array}{c}\text { Traço 1 } \\
\left(\boldsymbol{V}_{\boldsymbol{f}=\mathbf{0 , 0 0}}\right.\end{array}$} & \multicolumn{2}{c|}{$\begin{array}{c}\text { Traço 2 } \\
\left(\boldsymbol{V}_{\boldsymbol{f}}=\mathbf{0 , 5 0 \%}\right)\end{array}$} & \multicolumn{2}{c}{$\begin{array}{c}\text { Traço 3 } \\
\left(\boldsymbol{V}_{\boldsymbol{f}}=\mathbf{1 , 5 0 \%}\right)\end{array}$} \\
\hline Mistura & $\mathbf{1}^{\mathbf{0}}$ & $\mathbf{2}^{\mathbf{0}}$ & $\mathbf{1}^{\mathbf{0}}$ & $\mathbf{2}^{\mathbf{0}}$ & $\mathbf{1}^{\mathbf{0}}$ & $\mathbf{2}^{\mathbf{0}}$ \\
\hline Abatimento da matriz(cm) & 14,20 & 20,50 & 24,00 & 23,50 & 28,00 & 26,50 \\
\hline $\begin{array}{c}\text { Abatimento do concreto } \\
\text { com fibras }(\mathrm{cm})\end{array}$ & --- & --- & 21,00 & 21,50 & 3,00 & 6,00 \\
\hline Massa Específica $\left(\mathrm{kg} / \mathrm{m}^{3}\right)$ & 2426,67 & 2440,00 & 2533,33 & 2533,33 & 2606,67 & 2593,33 \\
\hline Teor de ar $(\%)$ & 2,15 & 2,10 & 1,60 & 1,50 & 1,90 & 1,60 \\
\hline
\end{tabular}

\subsection{Propriedades do concreto no estado endurecido}

Foram determinadas duas características mecânicas do concreto: (a) Resistência à compressão; e (b) Módulo de elasticidade inicial. Tal abordagem seguiu os procedimentos descritos na ABNT NBR 5739 [19] e a ABNT NBR 8522 [21], respectivamente, chegando aos resultados médios e desvio padrão apresentados na Tabela 5.

Tabela 5: Resultados médios dos ensaios de resistência à compressão e módulo de elasticidade:

\begin{tabular}{c|c|c|c|c|c}
\hline Traço & $\begin{array}{c}\text { Volume de } \\
\text { fibras }\left(\boldsymbol{V}_{\boldsymbol{f}}\right)\end{array}$ & $\begin{array}{c}\text { Resistência à } \\
\text { compressão }\left(\boldsymbol{f}_{c m}\right)- \\
\mathbf{M P a}\end{array}$ & $\begin{array}{c}\text { Módulo de elastici- } \\
\text { dade }\left(\boldsymbol{E}_{c m}\right)-\mathbf{G P a}\end{array}$ & $\begin{array}{c}E_{c m} \text { segundo } \\
\text { Model Code 2010 } \\
\text { [7] - GPa }\end{array}$ & $\begin{array}{c}E_{c m} \text { segundo } \\
\text { Araújo [11] - } \\
\mathbf{G P a}\end{array}$ \\
\hline Traço 1 & $0,00 \%$ & $60,23 \pm 2,91$ & $37,26 \pm 1,56$ & 40,78 & 35,51 \\
\hline Traço 2 & $0,50 \%$ & $70,78 \pm 3,96$ & $40,68 \pm 1,96$ & 42,78 & 38,50 \\
\hline Traço 3 & $1,50 \%$ & $75,89 \pm 4,57$ & $40,22 \pm 0,27$ & 43,69 & 39,86 \\
\hline
\end{tabular}

Foi realizado um tratamento estatístico dos dados da Tabela 5 por meio da análise de variância de fator único (ANOVA), adotando um intervalo de confiança de 5,00\%, e considerando dois traços por análise. Os resultados da análise estatística mostram que a presença das fibras de aço influenciou a resistência à compressão, a qual aumentou com a adição das fibras. Contudo, a resistência à compressão não foi influenciada pelo volume de fibras. Já o módulo de elasticidade não foi influenciado significativamente pela adição das fibras de aço.

\subsection{Curva tensão-deformação à compressão}

A curva tensão-deformação do concreto foi determinada experimentalmente conforme metodologia descrita no item 3 desse artigo. Na Figura 9 são apresentadas as curvas obtidas para os corpos de prova dos traços 1, 2 e 3. Percebe-se que o método de ensaio proposto neste artigo conseguiu capturar o trecho ascendente e descendente da curva tensão-deformação para todos os corpos de prova ensaiados. Notam-se algumas perturbações nas curvas do concreto simples e com baixo teor de fibras, que são devidas à ruína localizada do corpo de prova durante o ensaio. Apesar da resposta mais lenta da máquina de ensaio eletromecânica quando comparada a uma máquina servo-controlada, foi possível registrar a tendência das curvas no trecho pós-pico. No caso do concreto com maior volume de fibras, nota-se um comportamento mais estável durante todo o ensaio. 


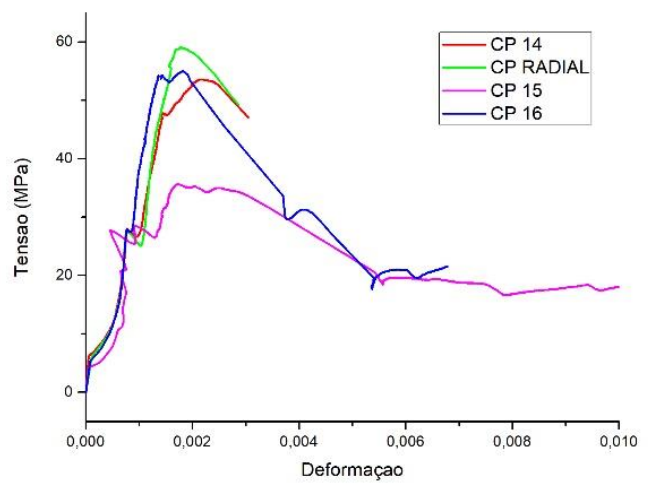

a) $\operatorname{Traço} 1\left(V_{f}=0,00 \%\right)$

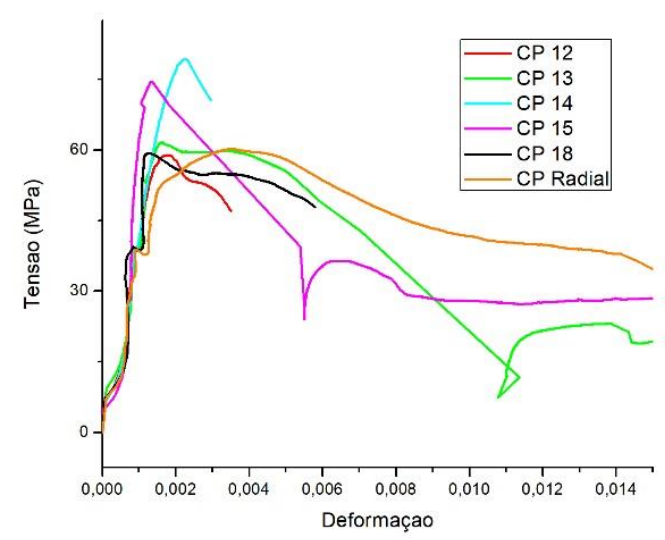

b) Traço $2\left(V_{f}=0,50 \%\right)$

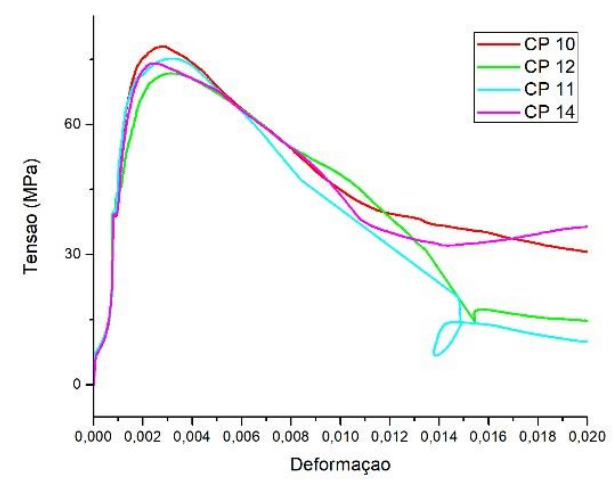

c) $\operatorname{Traço~} 3\left(V_{f}=1,50 \%\right)$

Figura 9: Curvas obtidas nos ensaios experimentais com máquina de baixo custo.

Visando a validação das curvas tensão-deformação obtidas, os resultados experimentais de deformação de pico do concreto foram comparados com valores sugeridos por alguns autores, a saber: (a) OLIVEIRA JÚNIOR et al. [8] (Equação 18); (b) CARREIRA e CHU [6] (Equação 19); (c) MANSUR et al. [9] (Equação 20); (c) BARROS e FIGUEIRAS [10] (Equação 21); (e) Model Code 2010 [7], que define a deformação de pico em função da classe de resistência do concreto; e (f) ARAÚJO [11] (Equação 6).

$$
\begin{gathered}
\varepsilon_{c, \text { lim }}=\left(0,00048+0,01886 \cdot V_{f}\right) \cdot \ln f_{0} \\
\varepsilon_{c, \text { lim }}=\left(0,71 \cdot f_{0}+168\right) \cdot 10^{-5} \\
\varepsilon_{c, \text { lim }}=\left[0,00050+0,00000072\left(\frac{V_{f} \cdot l}{d}\right)\right] \cdot f_{0}^{0,35} \\
\varepsilon_{c, \text { lim }}=0,0022+0,00085 \cdot V_{f}
\end{gathered}
$$

Nessas expressões, $\varepsilon_{c, l i m}$ é a deformação de pico do concreto, $f_{0}$ é a tensão máxima correspondente aplicada e $l / d$ é o fator de forma da fibra utilizada.

Os resultados obtidos são mostrados na Tabela 6. Com exceção do traço 2, o coeficiente de variação obtido nos valores experimentais da deformação de pico ficou em torno de $10,00 \%$.

De modo geral, e considerando a variabilidade observada nos ensaios, observa-se que a deformação de pico obtida experimentalmente ficou próxima dos valores recomendados na literatura. Com exceção do traba- 
lho de OLIVEIRA JÚNIOR et al. [8], em todos os demais foi utilizada uma máquina de ensaio servocontrolada para determinação das curvas tensão-deformação. Isso mostra que a metodologia utilizada neste trabalho se mostrou eficaz para avaliar a deformação de pico do concreto sem fibras e do concreto reforçado com fibras. A diferença mais significativa é com relação à deformação de pico recomenda pelo Model Code 2010 [7] para o concreto sem fibras, que foi maior que o valor superior encontrado no programa experimental. Contudo, a deformação experimental ficou próxima dos valores obtidos por CARREIRA e CHU [6] e MANSUR et al. [9].

Os resultados experimentais mostram, também, que as fibras de aço influenciaram a deformação de pico do concreto apenas para o volume de $1,50 \%$. Para o volume de $0,50 \%$, a presença das fibras provocou uma maior dispersão nos resultados experimentais, porém o valor da deformação de pico foi estatisticamente igual à do concreto sem fibras.

Tabela 6: Deformação de pico do concreto comprimido $\left(\times 10^{-3}\right)$.

\begin{tabular}{c|c|c|c|c|c|c|c|c}
\hline Traço & $\boldsymbol{f}_{\mathbf{0}} \mathbf{( M P a )}$ & $\boldsymbol{\varepsilon}_{c, \text { experimental }}$ & $\varepsilon_{c, \text { Carreira e Chu }}$ & $\varepsilon_{c, \text { Model Code }}$ & $\begin{array}{c}\boldsymbol{\varepsilon}_{c, \text { Oliveira e Junior }} \\
\text { et al }\end{array}$ & $\boldsymbol{\varepsilon}_{c, \text { Mansur et al. }}$ & $\boldsymbol{\varepsilon}_{c, \text { Araújo }}$ & $\varepsilon_{c, \text { Barros e Figueiras }}$ \\
\hline Traço 1 & 55,90 & $1,86 \pm 0,20$ & 2,08 & 2,60 & 1,93 & 2,04 & 2,29 & 2,20 \\
\hline Traço 2 & 62,92 & $1,98 \pm 0,88$ & - & - & 2,38 & 2,23 & 2,47 & 2,53 \\
\hline Traço 3 & 75,46 & $2,88 \pm 0,36$ & - & - & 3,30 & 2,59 & 3,03 & 3,18 \\
\hline
\end{tabular}

Na Figura 10 é feita a comparação da curva tensão-deformação experimental com algumas curvas propostas na literatura. Essas curvas estão normalizadas pela resistência à compressão de cada corpo de prova, permitindo uma melhor análise do trecho pós-pico das curvas obtidas. Para o concreto sem fibras, observa-se uma relativa aproximação da curva experimental com a curva proposta pelo Model Code 2010 [7], apesar da menor deformação de pico encontrada nos ensaios. Já para os corpos de prova com fibras, observa-se que as curvas propostas por Barros e Figueiras [10] e por Araújo [11] aproximaram-se bem das curvas obtidas neste trabalho. A boa aproximação no trecho pré-pico deve-se à proximidade do valor do módulo de elasticidade inicial obtido do ensaio com os valores determinados por Araújo [11], como mostrado na Tabela 5. Isso comprova a eficiência da metodologia de ensaio proposta neste trabalho para determinação da curva tensão-deformação do concreto à compressão, especialmente para o concreto reforçado com fibras de aço. 


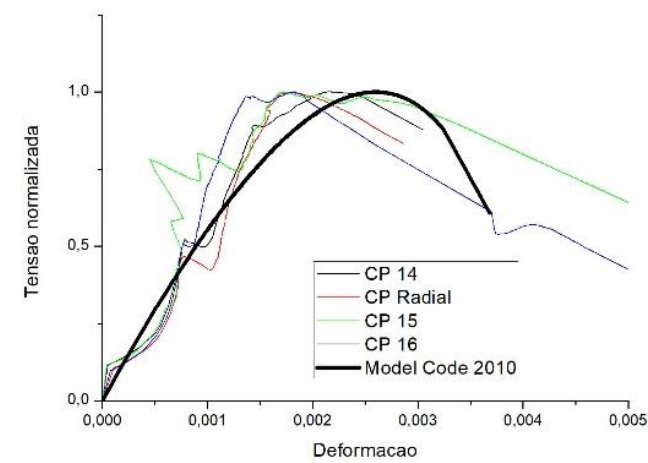

a) Traço 1

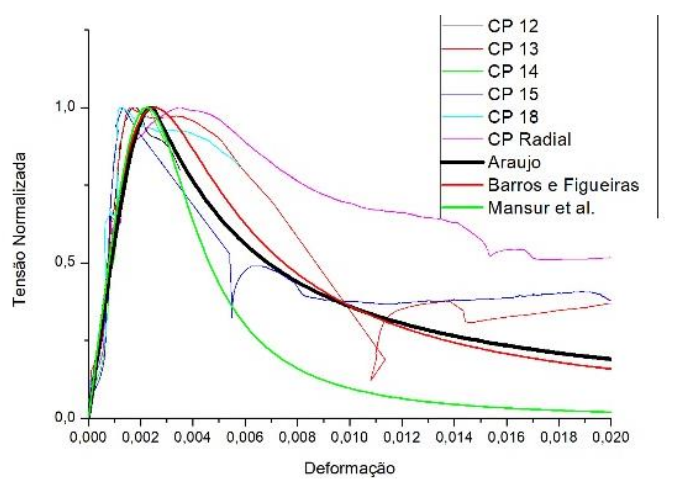

b) Traço 2

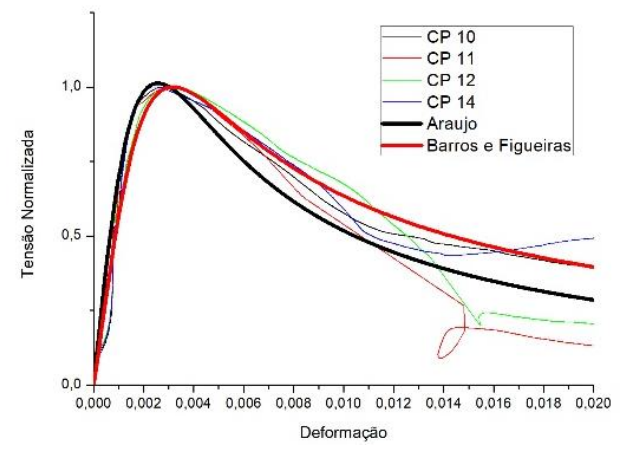

c) Traço 3

Figura 10: Comparação das curvas tensão-deformação à compressão do concreto com códigos de projeto e modelos empíricos.

\subsection{Curva tensão-deformação à compressão por análise inversa}

Para obtenção da curva numérica tensão-deformação do concreto sem fibras foi utilizada como referência a curva média experimental do Traço 1 com módulo de elasticidade $\left(E_{c}\right)$ de 37,26 GPa e coeficiente de Poisson igual a 0,20 . Vale ressaltar que para a determinação da curva média do Traço 1 foram eliminados do conjunto de dados os resultados referentes ao "CP 15" devido à sua grande discordância em relação aos outros resultados obtidos do Traço 1. O intervalo de análise das curvas foi limitado pela deformação máxima de 0,0040.

O processo de calibração do algoritmo ACV foi o mesmo realizado em Pereira Junior et al. [34] e os parâmetros empregados nessa modelagem numérica foram: $\beta 0=1,00, \gamma=1,00, \beta \min =0,10, \alpha=0,20, N P=$ 100 e Ngen $=400$.

Dois modelos para o concreto foram acoplados ao algoritmo de otimização: o modelo de dano de Mazars e Pijaudier-Cabot [29] e a equação empírica sugerida por Carreira e Chu [6] mostrada na equação (22). Para as variáveis do modelo de dano de Mazars e Pijaudier-Cabot [29] foi utilizado o intervalo proposto em [29] e apresentado em Pituba e Proença [35]. Já para a equação empírica (22) recomendada por Carreira e Chu [6], o intervalo adotado para as variáveis foi de 0,0010 a 0,0030 para a deformação de pico $\varepsilon_{c, l i m}$ e de 1,00 a 4,00 para a variável $\beta$. Onde $E_{c}$ representa o módulo de elasticidade do concreto ensaiado.

$$
\begin{aligned}
& \frac{\sigma_{c}}{f_{c}}=\frac{\beta \cdot \frac{\varepsilon_{c}}{\varepsilon_{c, l i m}}}{\beta-1+\left(\frac{\varepsilon_{c}}{\varepsilon_{c, l i m}}\right)^{\beta}} \\
& \beta=\frac{1}{1-\frac{\varepsilon_{c}}{\varepsilon_{c, l i m} \cdot E_{c}}}
\end{aligned}
$$

Neste trabalho, a rotina de otimização foi executada 10 vezes (10 pontos iniciais ou "sementes" diferentes) a fim de garantir que a população de vagalumes percorresse o maior espaço amostral possível, melhorando assim o fator de exploração do algoritmo. A curva tensão-deformação numérica foi definida como sen- 
do a que minimizava a Função Objetivo (FO) escolhida para o problema em questão, ou seja, que minimizava a distância entre as curvas numérica e experimental. A FO utilizada neste trabalho é mostrada nas equações (24) e (25).

$$
\begin{aligned}
& \sum_{i=1}^{N}\left(\frac{\sigma_{i}^{\text {calc }}-\sigma_{i}^{\text {exp }}}{\sigma_{i}^{\text {exp }}}\right)^{2} \\
& X_{i} \leq X \leq X_{f}
\end{aligned}
$$

Nessa equação, $\sigma_{i}^{e x p}$ é a tensão de compressão no corpo de prova obtida do ensaio, $\sigma_{i}^{\text {calc }}$ é a tensão de compressão numérica (obtida do modelo de dano proposto por [29] ou da equação empírica sugerida em [6]) e $N$ é o número de pontos experimentais do ensaio. As restrições do processo de otimização são dadas pelo intervalo adotado para as variáveis do problema, ou seja, as restrições dadas são restrições laterais.

Para consideração das restrições laterais foi utilizado um método de barreira ou penalidade, onde a FO é transformada em uma função pseudo objetivo $\phi$ conforme apresentada na equação (26) e (27).

$$
\begin{aligned}
& \phi=F O(X) \text { Se } X \in \text { Região viável } \\
& \phi=F O(X)+P(X) \text { Se } X \notin \text { Região viável }
\end{aligned}
$$

Para situações onde a função $P(\vec{x})$ é igual a zero (Equação 26), não houve violação das restrições. Caso ela seja positiva, houve violação das mesmas e, portanto, adiciona-se a penalidade ao equacionamento (Equação 27). Para esse artigo foi utilizado uma função de penalidade exterior dada na equação (28).

$$
P(X)=r p \cdot \sum_{j=1}^{m}\left\{\max \left[0, g_{j}(X)\right]\right\}^{2}+\sum_{k=1}^{n}\left[h_{k}(X)\right]^{2}
$$

Onde $g_{j}(X)$ são as restrições de desigualdade, $h_{k}(X)$ são as restrições de igualdade do problema analisado. Nesse caso, somente foram utilizadas restrições de desigualdade $g_{j}(X)$ e $r_{p}$ o fator de penalidade exterior foi fixado em $10^{6}$.

Empregando a equação empírica sugerida por Carreira e Chu [6], a curva tensão-deformação numérica obtida é mostrada na Figura 11a. Foram feitas 40.100 avaliações da FO por "semente" do modelo de otimização, sendo que para as dez sementes aplicadas obteve-se um total de 401.000 avaliações da FO em um tempo total de processamento de 124,85 segundos. Os resultados obtidos para as variáveis do problema foram: $\varepsilon_{c . l i m}$ $=0,0024262$ e $\beta=3,870391$. Neste caso, o valor obtido para a FO foi igual a 1,57741. Comparando a área sob a curva numérica com a área sob a curva experimental do traço 1 , a diferença foi de apenas $0,0158 \mathrm{MPa}$. A tensão de pico obtida para o modelo descrito pela equação de Carreira e Chu [6] foi de 60,21MPa enquanto no ensaio experimental foi de $54,57 \mathrm{MPa}$, isto é, uma diferença percentual de 10,34\%. Esses valores mostram que o algoritmo de otimização foi capaz de determinar as variáveis da equação empírica de Carreira e Chu [6] que representam o comportamento do corpo de prova ensaiado.

Empregando o modelo de dano proposto por Mazars e Pijaudier-Cabot [29], a curva tensãodeformação numérica obtida também é apresentada na Figura 11a. O valor obtido para a FO foi igual a 4,15015 com um tempo de processamento de 301,32 segundos para 401.000 avaliações da função objetivo. Os parâmetros do modelo de dano à compressão obtidos foram: $A_{c}=1,20 \mathrm{e} B_{c}=1093,9051$. A tensão de pico obtida foi igual a 56,80 MPa, com uma diferença de 4,09\% em relação ao valor experimental. Comparando a área sob a curva numérica com a área sob a curva experimental, a diferença foi de $13,11 \%$.

Para o emprego do modelo de dano foi utilizada para a deformação equivalente a tensão de pico na tração direta do concreto o valor de $\varepsilon_{\mathrm{do}}=0,00011074$. Tal deformação foi obtida utilizando a recomendação da ABNT NBR 6118 [4], conforme equação (29), já que esse parâmetro não foi determinado experimentalmente.

$$
f_{c t m}=2,12 \cdot \ln \left(1+0,11 \cdot f_{c k}\right)=2,12 \cdot \ln (1+0,11 \cdot 54,57)=4,126 M P a
$$

Sendo $f_{c t m}$ o valor da resistência à tração média do material. Para o valor de $f_{c k}$ foi utilizado o valor médio da resistência à compressão do concreto obtido do ensaio, isto é, 54,57 MPa. 

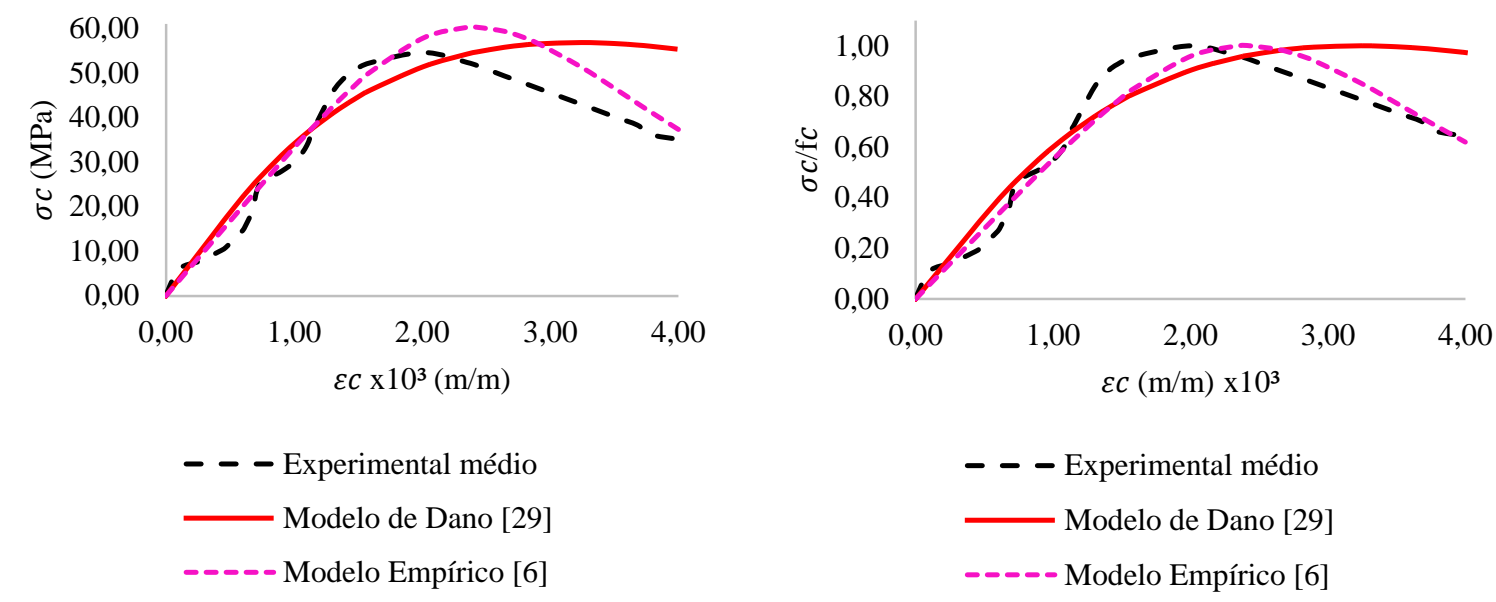

Figura 11: (a) Comparação das curvas tensão-deformação à compressão do concreto experimental Traço 1 com a modelagem numérica; (b) Comparação entre as curvas normalizadas.

A Figura 11b também apresenta uma comparação entre as curvas, porém normalizadas, o que permite observar com maior exatidão a diferença entre as curvas obtidas da análise inversa e a curva experimental, já que neste caso não há influência da tensão de pico. Verifica-se que a diferença entre a modelagem de dano [29] e os resultados experimentais para o intervalo analisado foi de 8,67\% enquanto para a análise inversa com a equação empírica proposta Carreira e Chu [6], a diferença foi de apenas $0,01 \%$.

\section{CONCLUSÃO}

Os resultados de caracterização do concreto mostraram que a adição de fibras de aço influenciou as propriedades da matriz de concreto no estado fresco quando comparado ao concreto simples. A maior influência foi observada com a adição de $1,5 \%$ de fibras de aço, quando foi observada uma redução no valor do abatimento da matriz de 27,25 cm para apenas 4,5 cm. De igual modo, a adição das fibras de aço influenciou a resistência à compressão do concreto, a qual aumentou com a adição das fibras. Contudo, a resistência à compressão não foi influenciada pelo volume de fibras. Já o módulo de elasticidade inicial do concreto não foi influenciado significativamente pela adição das fibras de aço.

Com relação à curva tensão-deformação à compressão do concreto, foco principal deste artigo, conclui-se que a metodologia de ensaio proposta, baseada nos trabalhos de MANSUR et al. [22] e da RILEM [23], foi satisfatória para se obter a curva tensão-deformação do concreto em uma prensa hidráulica acoplada a uma máquina de ensaio eletromecânica, que possui custo bem inferior ao de máquinas de ensaio servocontroladas. As curvas obtidas apresentaram boa concordância com curvas obtidas por outros pesquisadores para concretos reforçados com fibras de aço, em especial com os trabalhos de Barros e Figueiras [10] e Araújo [11], tanto no que diz respeito à deformação de pico do material quanto a forma da curva nos trechos prépico e pós-pico de resistência. Também para o concreto sem fibras, observou-se uma boa concordância entre a curva experimental e a curva proposta pelo Model Code 2010 [7], demonstrando a aplicabilidade dessa metodologia mesmo em concretos com ruínas mais frágeis.

A análise inversa empregando algoritmos de otimização metaheurísticos, neste caso a colônia de vagalumes, mostrou-se satisfatória para a determinação dos parâmetros de curvas tensão-deformação do concreto, visto que outros métodos numéricos, tais como o de mínimos quadrados, requerem uma quantidade maior de testes, fazendo com que o usuário avalie cada variável separadamente até o completo ajuste da curva. No caso da aplicação metaheurística, foi necessária apenas a descrição do intervalo de busca das variáveis de projeto e o próprio algoritmo retornou os valores mais adequados para o tipo de ajuste desejado. Nesse caso o intervalo adotado para as variáveis de projeto, quando foi empregado o modelo de dano, foi o mesmo proposto em Mazars e Pijaudier-Cabot [29].

A análise inversa empregando o modelo de dano no ensaio de compressão simples resultou em uma curva numérica com diferença menor que 4,50\% entre os valores experimental e numérico da tensão de pico do material e quando comparada a área sob a curva tensão-deformação, o erro ficou em torno de $13 \%$. Porém, a curva obtida via otimização não foi satisfatória no trecho pós-pico. Isso deve-se à simplicidade do 
modelo de dano adotado, que possui apenas duas variáveis de estado para determinação dos efeitos à compressão. Outros modelos de dano devem ser testados para se obter um melhor ajuste da curva numérica no trecho pós-pico.

A análise inversa com o modelo empírico de Carreira e Chu [6] apresentou uma maior diferença entre a tensão de pico numérica e experimental (erro em torno de 8\%) quando comparado ao modelo de dano. Porém, houve uma melhor correlação entre a curva obtido com o modelo de Carreira e Chu [6] e o resultado experimental. Fato o qual é explicado por se tratar de um modelo de dano com poucos parâmetros, portanto a qualidade da resposta pós pico é afetada nesse sentido. $\mathrm{O}$ modelo de dano estudado não permite uma redução acentuada da variável de dano em curto espaço de evolução da deformação como ocorre em matérias frágeis em tração como o concreto.

Logo outros modelos de dano ou modelos para concreto devem ser testados para se obter um melhor ajuste da curva numérica no trecho pós-pico. Também deve-se verificar a aplicabilidade de outros modelos de otimização ou diferentes tratamentos das restrições do problema a fim de uma tentativa de melhoria da resposta obtida.

\section{AGRADECIMENTOS}

Os autores agradecem ao CNPq e FAPEG pela concessão das bolsas de Iniciação Cientifica e de pesquisador, assim como o financiamento dessa pesquisa por meio do Edital Universal 14/2004. Agradecem, também, às empresas Bekaert, Votorantim, Mold Estruturas e Britagran pela doação de materiais utilizados na pesquisa.

\section{BIBLIOGRAFIA}

[1] HAJEK, P., "Concrete structures for sustainability in a changing world", Procedia Engineering, n.171, pp. 207-214, 2017.

[2] PENG, X., MEYER, C., "A continuum damage mechanics model for concrete reinforced with randomly distributed short fibers”, Computers \& Structures, v. 78, pp. 505-515, 2000.

[3] PEREIRA JUNIOR, W. M.; PITUBA, J. J. C., ARAÚJO, D. L., "Numerical analysis of steel fiber reinforced concrete beams using damage mechanics", Ibracon Structures and Materials Journal, v. 9, pp 153$191,2016$.

[4] ABNT NBR 6118: Projeto de estruturas de concreto - Procedimento. Rio de Janeiro, 2014.

[5] MEDEIROS, R, PEREIRA, B.A., SIPP, G, DELFINO, T., et al., "Investigation of the influence of different surface regularization methods for cylindrical concrete specimens in axial compression tests", Ibracon Structures and Materials Journal, v. 10, n. 3, pp. 568-591, 2017.

[6] CARREIRA, D. J., CHU, K., "Stress-strain relationship for plain concrete in compression", Journal of the American Concrete Institute, Proceedings, v.82, n.6, p.797-804, 1985.

[7] FIB - FÉDÉRATION INTERNATIONALE DU BÉTON. Model Code 2010: Final draft. Lausanne: International Federation for Structural Concrete, 2012. Volume 1, Bulletin 65.

[8] OLIVEIRA JUNIOR, L. A., BORGES, V.E.S., DANIN, A. R., et al., "Stress-strain curves for steel fiberreinforced concrete in compression", Revista Matéria, v. 15, n. 2, pp. 260-266, 2010.

[9] MANSUR, M. A., CHIN. M. S., WEE, T. H., "Stress-strain relationship of high-strength fiber concrete in compression", Journal of Materials in Civil Engineering, v. 11, n. 1, pp. 21-29, 1999.

[10] BARROS, J.A.O., FIGUEIRAS, J.A., "Flexural Behavior of SFRC: Testing and Modeling", Journal of Materials in Civil Engineering, v.11, n.4, p.331-339, 1999.

[11] ARAÚJO, D. L. Cisalhamento entre viga e laje pré-moldadas ligadas mediante nichos preenchidos com concreto de alto desempenho, Tese D.Sc., EESC/USP, São Carlos, SP, 2002.

[12] WIKMAN, B., BERGMAN, G., OLDENBURG, M., HÄGGBLAD, H.-Å., "Estimation of constitutive parameters for powder pressing by inverse modelling”, Structural and Multidisciplinary Optimization, v. 31, pp. 400-409, 2005.

[13] ABNT NBR 7211: Agregados para concreto - Especificação. Rio de Janeiro, 2005. 
[14] ABNT NBR 7251: Agregado em estado solto - Determinação da massa unitária. Rio de Janeiro, 1982.

[15] ABNT NBR NM 53: Agregado graúdo - Determinação da massa específica, massa específica aparente e absorção de água. Rio de Janeiro, 2003.

[16] BELGO BEKAERT, http://www.belgobekaert.com.br/Produtos/Paginas/Fibra-de-Aco-Dramix.aspx Acesso em 11 de junho de 2017.

[17] ABNT NBR NM 67: Concreto - Determinação da consistência pelo abatimento do tronco de cone. Rio de Janeiro, 1998.

[18] ABNT NBR 9833: Concreto fresco - Determinação da massa específica, do rendimento e do teor de ar pelo método gravimétrico. Rio de Janeiro, 2008.

[19] ABNT NBR 5739: Concreto - Ensaio de compressão de corpos-de-prova cilíndricos. Rio de Janeiro, 2007.

[20] ABNT NBR 5738: Concreto - Procedimento para moldagem e cura de corpos-de-prova. Rio de Janeiro, 2015.

[21] ABNT Rio de Janeiro, 2008.

[22] MANSUR, M. A., WEE, T.H., CHIN, M.S., "Derivation of the complete stress-strain curves for concrete in compression", Magazine of Concrete Research, v.47, n.173, pp.185-290, 1995.

[23] RILEM TC 148-SSC: STRAIN SOFTENING OF CONCRETE - TEST METHODS FOR COMPRESSIVE SOFTENING. "Test method for measurement of the strain-softening behavior of concrete under uniaxial compression", Material and Structures, v.33, pp.347-351, 2000.

[24] KHALFALLAH, A., SALAH, H. B. H., et al., "Anisotropic parameter identification using inhomogeneous tensile test", European Journal of Mechanics A/Solids, v. 21, pp. 927-942, 2002.

[25] OLIVEIRA, S., TOADER, A.M., VIEIRA, P., "Damage identification in a concrete dam by fitting measured modal parameters", Nonlinear Analysis: Real World Applications, v. 13, pp. 2888-2899, 2012.

[26] WARDEH, M. A., TOUTANJI, H. A., "Parameter estimation of a anisiotropic damage model for concrete using genetic algorithms", International Journal of Damage Mechanics, v. 26, n. 6, pp. 801-825, 2015.

[27] EBRAHIMIAN, H., KOHLER, M., MASSARI, A., et al., "Parametric estimation of dispersive viscoelastic layered media with application to structural health monitoring", Soil Dynamics and Earthquake Engineering, v. 105, p. 204-223, 2018.

[28] YANG, X. S. Nature Inspired Metaheuristic Algorithms, 2º ed., Editora: Luniver Press, 2008.

[29] MAZARS, J., PIJAUDIER-CABOT, G., "Continuum damage theory: application to concrete", Journal of Engineering Mechanics, v. 115, n. 2, p. 345-365, 1989.

[30] KENNEDY, J., EBERHART, R. C., "Particle swarm optimization", In: Proceedings of the 1995 IEEE International Conference on Neural Networks, v. 4, pp. 1942 - 1948, Perth, Australia, IEEE Service Center, Piscataway, NJ, 1995.

[31] FISTER, I., YANG, X.-S., BREST, J., et al., "Modified firefly algorithm using quaternion representation”, Expert Systems with Applications, v. 40, pp. 7220-7230, 2013.

[32] GOMES, H. M., RODRIGUES, E. R., "Algoritmo Meta-Heurístico de Vaga-Lume para a Otimização Estrutural em Tamanho e Forma com Restrições de Frequências Naturais", Engenharia Estudo e Pesquisa, v. 11, pp. 3-15, 2011.

[33] WANG, H., WANG, W., ZHOU, X., et al., "Firefly Algorithm with Neighborhood Attraction", Information Sciences, 2016.

[34] PEREIRA JUNIOR, W. M., SARMENTO, A. P., DANTAS, M. J. P., et al., "Avaliação dos parâmetros do algoritmo de colônia de vagalumes (ACV)", In: II Encontro de Pesquisa, Ensino e Extensão em Engenharia Civil, Catalão, Goiás, Brasil, 06-11 Novembro 2018. 
[35] PITUBA, J. J. C., PROENÇA, S. P. B. "Estudo e Aplicação de Modelos Constitutivos para o Concreto Fundamentados na Mecânica do Dano Contínuo", Cadernos de Engenharia de Estruturas (USP), v. 7, p. 3360, 2005.

\section{ORCID}

José Carlos Nunes Rauecker

https://orcid.org/0000-0003-0987-5877

Wanderlei Malaquias Pereira Junior

https://orcid.org/0000-0002-7404-3666

Jose Júlio de Cerqueira Pituba

https://orcid.org/0000-0002-1480-6238

Daniel de Lima Araújo

https://orcid.org/0000-0002-6802-4637 